\title{
Study the Transverse Vibration of a Beam With Different Length
}

\author{
Sabah Mohammed Jamel Ali \\ Professor \\ Ziad Shakeeb Al-Sarraf \\ Assistant Leacture \\ Mechanical Engineering Department, College of Engineering, Mosul University
}

\begin{abstract}
A numerical solution to the frequency equation for the transverse vibration of a beam (Simply Supported with symmetric overhang) is done. It is proposed two limiting cases of a beam with no overhang, and no span. This agrees with the cases in which the supports are at the nodal Points of a freely vibrating beam. Also the numerical results compared with the analytical solutions for this study are coincident.

An approximation to the solution of the frequency equation for beams with small overhang is presented and compared with the numerical solution. This approximation is quite useful to determine a beam's flexural stiffness (EI), or modulus of elasticity (E), by free vibrating of a simply supported beam.
\end{abstract}

Key word : Transverse vibration, beam, frequency

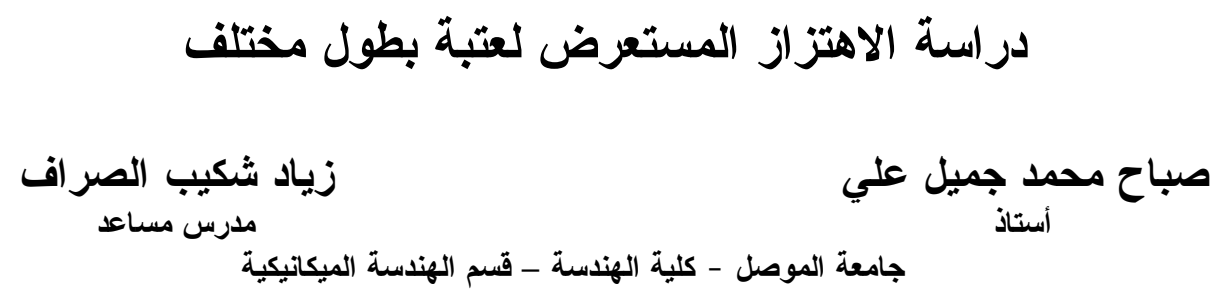

الخلاصة

نم إكمال الحل العددي لمعادلة التزدد للاهنز از المستعرض لعنبة مثنتة من نوع النتبيت البسيط مع وجود جزء

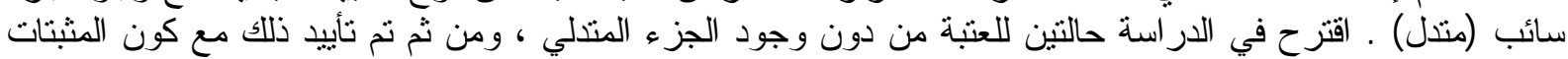

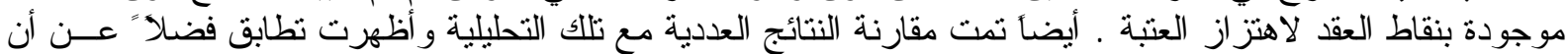

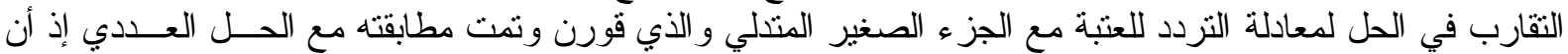

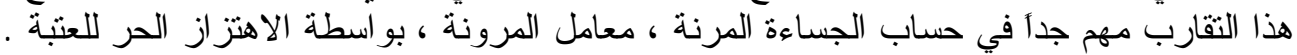
الكلمات الالة : اهتزاز مستعرض ، عنبة ، نردد . 


\section{$\begin{array}{llll}\text { Al-Rafidain Engineering } & \text { Vol.17 } & \text { No.1 } & \text { Feb. } 2009\end{array}$}

$\begin{array}{ll}\text { Nomenclature: } & \\ \mathrm{A} & \text { Beam Cross-section area }\left(\mathrm{m}^{2}\right) \\ \mathrm{C}_{1}, \mathrm{C}_{2}, \mathrm{C}_{3}, \mathrm{C}_{4} & \text { Constant } \\ \mathrm{E} & \text { Beam Young modulus of elasticity }\left(\mathrm{N} / \mathrm{m}^{2}\right) \\ \mathrm{I} & \text { Beam Second moment of area }\left(\mathrm{m}^{4}\right) \\ \mathrm{K}_{1} & \text { Fundamental root of frequency equation } \\ \mathrm{L} & \text { Length of the Beam }(\mathrm{m}) \\ \mathrm{EI} & \text { Dynamic flexural stiffness } \\ \mathrm{B} & \text { Base. horizontal dimension (length) } \\ \mathrm{H} & \text { Height, vertical dimension }(\text { length) } \\ \mathrm{g} & \text { Acceleration of Gravity }\left(\mathrm{m} / \mathrm{Sec}^{2}\right) \\ \mathrm{X} 1, \mathrm{X} 2, \mathrm{X} 3 & \text { Normal Function } \\ \mathrm{W} & \text { Total Beam Weight }(\mathrm{kg}) \\ \mathrm{W} / \mathrm{gL} & \text { Beam mass / Weight } \\ \mathrm{E}_{\text {calculated }} & \text { E calculated from equation (9) } \\ \mathrm{E}_{\text {true }} & \text { Best estimated E } \\ \mathrm{E}_{\text {overhang }} & \text { factor to account for specimen overhang at supports } \\ \mathrm{F}_{\text {shear }} & \text { factor to account for shearing deformations and rotary inertia } \\ \mathrm{F}_{\text {support }} & \text { factor to account for non-rigid supports } \\ \mathrm{F}_{\mathrm{I}}, \mathrm{F}_{\mathrm{W}}, \mathrm{F}_{\mathrm{K}} & \text { Factor of account [13] } \\ \rho & \left.\text { Beam Mass Density (kg/m }{ }^{3}\right) \\ f & \text { Beam Natural Frequency (H) } \\ \mathrm{t} & \text { Time (sec) } \\ \delta & \text { Beam Overhang (mm) } \\ \mathrm{S} & \text { Beam Span (mm) }\end{array}$

\section{Introduction:}

Since the mid-seventies the dynamic behavior of cracked shaft has been investigated increasingly because damages in turbines, generators, pumps, and other machines occurred quite often. This caused costly shutdowns of entire plants and was sometimes followed by the total loss of the machine. Fracture of a shaft which means crack are originated at points of stress concentration either inherent in design or introduced during fabrication on or operation. Cracks defined as micro or macro interrupt the system in principle is unavoidable. Also the initiation occurs during the vibration especially when the shaft is unbalance or miss-alignment [1].

Timoshenko and others [1] account for shearing deformations on the flexural vibration of beams. Note that this factor is slightly conservative (E calculated $<\mathrm{E}$ true).

For $\mathrm{h} / \mathrm{S}=1.5 / 94=0.0166, \mathrm{~F}$ shear $=0.996$; for $\mathrm{h} / \mathrm{S}=1.5 / 70=0.021, \mathrm{~F}$ shear $=0.992$. As $\mathrm{h} / \mathrm{S}$ increases, the correction factor $\mathrm{F}$ shear becomes more conservative.

Pellerin [2] was investigated the use of transverse vibrations of beams to determine the modulus of elasticity, E, of lumber and then predict strength. He examined free vibration of two systems. One was a beam freely supported at two nodal points, and the other was a beam simply supported at the ends. These two systems have analytical solutions to the equations of motion and can be found in the literature [3,7]. In these two cases, the supports are located at distances 0.224 times the length of the beam from the ends (nodal points), and at the ends of the beam. Dimarogonas and Papadopoulos [10] have computed the flexibility matrix for a beam, They have modeled the longitudinal and bending vibrations with $2 \times 2$-flexibility matrix [6]. For stress analysis purposes, Rice and Levy [11] computed the local flexibility corresponding to tension and bending, including their coupling terms.. Dimarogonas and 
Massouros [12], combined this spring hinge model and developed a frequency spectral method to identify any cracks in various structures or beams.

In practice, a beam has some overhang and is never supported at its extreme ends. In this search, the vibration of a beam with an overhang of different length is investigated numerically, an approximate formula for small overhang is proposed, and the results are compared.

\section{Determine the natural Frequency:}

In order to determine the natural frequency (f), of a beam (simply supported with symmetric overhang) of different length, we use the methodology used by Timoshenko [3] and Seto [5] and for brevity refer the reader to these publications. Also, we assume that the cross-sectional dimensions of the beam are constant and small in comparison to its length this is by ignoring the effects of rotary inertia and shearing deformations. A beam vibrates transversely in one of its natural modes, the deflection at any location Varies harmonically with time (t), as follows:

$$
y=X(A \cos 2 \pi f t+B \sin 2 \pi f t)
$$

Where $\mathrm{X}$ is strictly a function called a (normal function) of distance (x) along the beam and satisfies a fourth-order ordinary differential equation which can be written as [7]: -

$$
X^{4}-K^{4} X=0 .
$$

The general solution to this differential equation has the following form:

$$
X(x)=C 1 \cos k x+C 2 \sin k x+C 3 \cosh k x+C 4 \sinh k x
$$

And for transverse vibration of beams:

$$
K^{4}=\frac{(2 \pi f)^{2}}{\left(\frac{\rho A}{E I}\right)}
$$

The constant (C1) to (C4) must be determined from the boundary conditions at the ends of the beam. Solve for these constant leads to the frequency equation specification for the boundary conditions under consideration.

For the considered beam (simply supported with symmetric overhang), it is divide into three sections with three coordinate systems and origins. As Shown in (Fig.1) below for beam geometry.

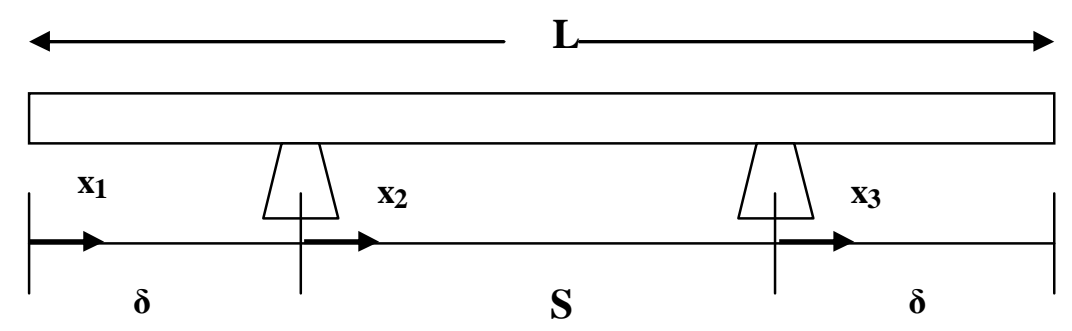

Fig.1 Geometry of Beam with an Overhang 
Let $\mathrm{X} 1, \mathrm{X} 2$, and $\mathrm{X} 3$ be the normal functions of the beam sections [4,5]. The general solution for the normal functions can be expressed as:-

$\begin{array}{ll}\mathrm{X} 1=\mathrm{A} 1 \cos \mathrm{kx} 1+\mathrm{B} 1 \cosh \mathrm{kx} 1+\mathrm{C} 1 \sin \mathrm{kx} 1+\mathrm{D} 1 \sinh \mathrm{kx} 1 & \text { for } 0 \leq X 1 \leq \delta \\ \mathrm{X} 2=\mathrm{A} 2 \cos \mathrm{kx} 2+\mathrm{B} 2 \cosh \mathrm{kx} 2+\mathrm{C} 2 \sin \mathrm{kx} 2+\mathrm{D} 2 \sinh \mathrm{kx} 2 & \text { for } 0 \leq X 2 \leq \delta \\ \mathrm{X} 3=\mathrm{A} 3 \cos \mathrm{kx} 3+\mathrm{B} 3 \cosh \mathrm{kx} 3+\mathrm{C} 3 \sin \mathrm{kx} 3+\mathrm{D} 3 \sinh \mathrm{kx} 3 & \text { for } 0 \leq X 3 \leq \delta\end{array}$

With these three normal functions, we have to satisfy a number of boundary conditions. Due to the Principle of Strength of Material [6,8], the ends of the beam both moment and shear are zero. Also at the midpoint, deflection is zero, slope and moment are continuous. These (12) boundary conditions are expressed mathematically as follows:

$$
\begin{aligned}
& \text { at } x_{1}=0 \\
& \frac{d^{2} X 1}{d x_{1}^{2}}=0 \\
& \frac{d^{3} X 1}{d x_{1}^{3}}=0 \\
& \text { at } x_{1}=\delta, x_{2}=0, X 1=0 \\
& X 2=0 \\
& \frac{d X 1}{d x_{1}}-\frac{d X 2}{d x 2}=0 \\
& d^{2} X 1 d x_{1}^{2}-\frac{d^{2} X 2}{d x^{2}}=0 \\
& \text { at } x_{2}=S, x 3=0, X 2=0 \\
& X 3=0 \\
& \frac{d X 2}{d x_{2}}-\frac{d X 3}{d x_{3}}=0 \\
& \frac{d^{2} X 2}{d x_{2}{ }^{2}}-\frac{d^{2} X_{3}}{d x_{3}{ }^{2}}=0 \\
& \text { at } x_{3}=\delta, \frac{d^{2} X_{3}}{d x_{3}{ }^{2}}=0 \\
& \frac{d^{3} X_{3}}{d x_{3}{ }^{3}}=0
\end{aligned}
$$

Where $(\delta)$ is beam overhang with $(0<\delta)$, (S) is beam span with $(0<\mathrm{S})$, and (L) is beam length with the $(\mathrm{S}<\mathrm{L})$. If we define $(\alpha=\mathrm{S} / \mathrm{L})$ as the ratio of span to length, then the overhang can be expressed as $(\delta=\mathrm{L}(1-\alpha) / 2)$. 
From the boundary conditions and the normal functions we can construct a $(12 \times 12)$ matrix of the coefficients of the (12) constants. The elements of the matrix consist of the trigonometric and hyperbolic terms of the normal functions is constructed. At $\mathrm{x} 1, \mathrm{x} 2, \mathrm{x} 3=0$ the arguments of their respective terms are zero.

At $x 1, x 3=\delta$ the arguments of their respective terms are $k \delta$, that is $k L(1-\alpha) / 2$. At $\left(x_{2}\right.$ $=\mathrm{S})$ the arguments of its terms are $\mathrm{kS}$, that is $\mathrm{kLa}$. Therefore all the arguments are either zero or $\mathrm{kL}(1-\alpha) / 2$ or $\mathrm{kL} \alpha$. If a (span to length ratio) is fixed, then the arguments are a function of $\mathrm{kL}$ only.

This set of (12) homogeneous equations will have non-trivial solutions only if the determinant of the coefficients vanishes. Expansion of the $(12 \times 12)$ determinant is the frequency equation for a simply supported beam with symmetric overhang. Roots of the frequency equation, numerical values of $\mathrm{kL}$ forcing the determinant to vanish, correspond to the natural frequencies.

We are interested in the first non-zero root, the $\mathrm{kL}$ value that corresponds to the fundamental natural frequency. Thus, the minimum non-zero $\mathrm{kL}$ value that makes the determinant zero will be used to calculate the fundamental frequency (specific for the overhang corresponding to the chosen a). We re-write Eq 3 as:

$$
\begin{aligned}
f & =\frac{k^{2}}{2 \pi} \sqrt{\frac{E I}{\rho A}} \\
& =\frac{(k L)^{2}}{2 \pi} \sqrt{\frac{E I}{L^{4} \rho A}} \\
f^{2} & =\left(\frac{(k L)^{2}}{2 \pi}\right)^{2} \frac{E I}{L^{4} \rho A}
\end{aligned}
$$

We define $\mathrm{K}_{1}$ as the transformed fundamental root of the frequency equation:

$$
\begin{aligned}
k_{1} & =\left(\frac{(k L)^{2}}{2 \pi}\right)^{2} \\
f^{2} & =k_{1} \frac{E I}{L^{4} \rho A} \\
& =k_{1} \frac{E I g L}{L^{4} W}
\end{aligned}
$$

where:

$g=$ acceleration of Gravity

$W=$ total beam weight

$\frac{W}{g L}=$ beam mass / length

\section{The Steps of Calculation:}

Select a value for $\alpha$ ratio of span to length (S/L) with $(1>\alpha>0)$. For $\alpha=1$ or $\alpha=0$ with a special values of $\mathrm{kL}$. Then Find the determinant of the $(12 \times 12)$ matrix by (a). Using Gaussian elimination program. Multiplying the diagonal terms to calculate the determinant. Check the determinant against a very small number until the determinant is close enough to zero. Calculate $\mathrm{K}_{1}=\left[(\mathrm{kL})^{2} /(2 \pi)\right]^{2}$, this $\mathrm{K}_{1}$ is specific for the a being investigated. 


\section{Idealized Equation}

The following idealized equation from Timoshenko and others (1974) is used to calculate flexural stiffness EI using transverse vibration of a simply end-supported beam:

$$
E I=\frac{f^{2} L^{4} W}{\left(\frac{\pi}{2}\right)^{2} g L}
$$

Equation (7) was derived for an idealized homogenous material with constant cross section and rigid supports at the extreme ends of the member for boundary conditions rectangular shape (lumber), which, although not necessary (for example, the method is valid for constant cross section, I shape, T shape,), further defines the moment of inertia I:

$$
I=\frac{b h^{3}}{12}
$$

The idealized equation takes the final form

$$
E=\frac{f^{2} L^{4}}{K b h^{3}} \frac{W}{L}=\frac{f^{2} L^{3} W}{K b h^{3}}=\frac{f^{2} W}{K b}\left(\frac{L}{h^{3}}\right)
$$

where the constant $\mathrm{K}=(\pi / 2)^{2} \mathrm{~g} / 12$ (that is, $201.641 \mathrm{~cm} / \mathrm{s} 2,79.386 \mathrm{in} / \mathrm{s} 2$ ). This commentary discusses six factors that affect the calculated flexural modulus of elasticity $\mathrm{E}$ using Equation (9). The six factors are multiplicative [13] :

$$
E_{\text {calculated }}=E_{\text {true }} F_{\text {overhang }} F_{\text {shear }} F_{\text {sup port }} F_{I} F_{W} F_{K}
$$

\section{Overhang}

Numerically investigated the effect of symmetric overhang on the transverse vibration of a beam (beam in the generic sense) with matching results for beams with rigid supports at the ends (span-to-length ratio $\mathrm{S} / \mathrm{L}=1$, where $\mathrm{S}$ is span), rigid supports at mid-span $(\mathrm{S} / \mathrm{L}=0)$, and a free-free condition $(\mathrm{S} / \mathrm{L}=0.442)$. It developed an analytic approximation to the vibration equation for small symmetric overhang. His equation accounting for overhang is

$$
E I=\frac{f^{2} S^{4}}{\left(\frac{\pi}{2}\right)^{2}} \frac{W}{g L}
$$

Comparing Equations (11) and (7) results in the definition of the overhang factor

$$
F_{\text {overhang }}=\left(\frac{L}{S}\right)^{4}
$$

Table.(1) the un conservative error $\left(E_{\text {calculated }}>E_{\text {true }}\right)$ associated with ignoring overhang are introduced. Some transverse vibration systems that use software based on Equation (9) ask only for the input of $\mathrm{L}$. 
Table 1-Overhang (symmetric) factor

\begin{tabular}{|c|c|c|c|c|c|c|}
\hline \multirow{2}{*}{ Length } & L/S & $\overline{(\mathrm{L} / \mathrm{S}) 4}$ & L/S & $\overline{(\mathrm{L} / \mathrm{S}) 4}$ & L/S & $\overline{(\mathrm{L} / \mathrm{S})^{4}}$ \\
\hline & \multicolumn{2}{|c|}{ 1-in overhang } & \multicolumn{2}{|c|}{ 2-in overhang } & \multicolumn{2}{|c|}{ 4-in overhang } \\
\hline 72 & 1.03 & 1.12 & 1.06 & 1.26 & 1.13 & 1.60 \\
\hline 96 & 1.02 & 1.09 & 1.04 & 1.19 & 1.09 & 1.42 \\
\hline 120 & 1.02 & 1.07 & 1.03 & 1.15 & 1.07 & 1.32 \\
\hline 144 & 1.01 & 1.06 & 1.03 & 1.12 & 1.06 & 1.26 \\
\hline
\end{tabular}

For this software. due to overhang could be minimized if span $\mathrm{S}$ were input in place of specimen length $\mathrm{L}$. Then the error could be L/S rather than $(\mathrm{L} / \mathrm{S})^{4}$ because the mass per unit length would be incorrect using span instead of length. Considering overhang, it is recommended to :

- use a corrected formula (Eq. (11)) to explicitly account for overhang or

- with systems that utilize Equation (9), use span S rather than specimen length L.

\section{Constant K}

The constant $\mathrm{K}$ in Equation (3) theoretically should be $[(\pi / 2) 2(\mathrm{~g} / 12)]$. If a different $\mathrm{K}$ is used, then the factor accounting for this is

$$
F_{K}=\frac{\left(\frac{\pi}{2}\right)^{2}\left(\frac{g}{12}\right)}{K}
$$

As shown, if the $\mathrm{K}$ used is greater than the theoretical value, then $\mathrm{E}_{\text {calculated }}<\mathrm{E}_{\text {true }}$ and if less, $\mathrm{E}_{\text {calculated }}>\mathrm{E}_{\text {true. }}$. Considering the constant $\mathrm{K}$, it is recommended to

- set $\mathrm{K}$ to its theoretical value or

- set $\mathrm{K}$ to $\mathrm{L} / \mathrm{S}$ times its theoretical value only when $\mathrm{S}$ is substituted for the $\mathrm{L}$ in the Equation (9).

\section{Results:}

The lower solid curve in (Fig. 2) is $\mathrm{K}_{1}$ computed as described as a function of (S/L). As (S/L) approaches $1, \mathrm{~K}_{1}$ numerically converges to (2.47) which agrees with the analytical solution [3] of a simply supported beam with no overhang $\left(\left[(\pi)^{2} /(2 \pi)\right]^{2}\right)$.

As $(\mathrm{S} / \mathrm{L}=0.56),(\delta=0.22 \mathrm{~L}), \mathrm{K}_{1}$ is $(12.68)$ which agrees with the analytical solution [3] of a (free-free) beam with nodal (no deflection) points at $(0.22 \mathrm{~L}$ ) and $(0.78 \mathrm{~L})$, $\left(\left[(4.73)^{2} /(2 \pi)\right]^{2}\right)$.

As (S/L) approaches $0, K_{1}$ numerically converges to (5.001) which agrees with the adjusted analytical solution [7] of two back-to-back (fixed-end to fixed end) cantilever beams $\left(\left[(1.875 \times 2)^{2} /(2 \pi)\right]^{2}\right)$.

For small values of $(\delta)$, we ignore the overhang while still keeping the same beam mass per unit length, we would substitute $\left(\mathrm{S}^{4}\right)$ for $\left(\mathrm{L}^{4}\right)$ and use $(2.47)$. The approximation for $\mathrm{K}_{1}$ is then plotted as the curve in Fig. 2.

$k_{1} \cong 2.47 \frac{L^{4}}{S^{4}}$

At $(\mathrm{S} / \mathrm{L}=0.85)$ the ratio of the approximation to numerical solution is (1.009) while at $(\mathrm{S} / \mathrm{L}=0.80)$ the ratio is (1.026). Substituting this approximation into Eq 6 results in a simple 
approximation of the solution to the frequency equation for beams (simply supported with symmetric overhang):-

$$
f^{2} \cong 2.47 \frac{E I g L}{S^{4} W}
$$

Transverse vibration is used to first calculate stiffness EI and then E, using a measured or assumed I. It is extremely important to be consistent in research which I is used. If a regression is developed (for example, strength versus E) using one I (for example, measured), then it should be noted so that the other I (for example, assumed nominal) is not accidentally used in it subsequently.

Also, an apparent change in the quality of the forest resource, as measured by $\mathrm{E}$ calculated, might actually be attributed to a change in dimension if nominal dimensions are used.

Buckling is dependent on $\mathrm{E}$; therefore, the engineer using $\mathrm{E}$ measured by transverse vibration has to be made aware of exactly how $\mathrm{E}$ was calculated.

\section{Conclusions:}

The numerical solution of the frequency equation of the free transverse vibration of a simply supported beam with symmetric overhang of arbitrary length is presented.

A simple analytical approximation to the numerical solution for the case of small overhang is shown to be quite good for $\left(1 \geq \frac{S}{L} \geq 0.85\right)$ and reasonable for $\left(0.85 \geq \frac{S}{L} \geq 0.80\right)$.

The approximation valid for a vibrating beam (Simply supported with small overhang), can be used to compute a beam's flexural stiffness (EI) from measured frequency $(f)$, measured geometry (S, L, and W) and could result in a conservative estimate of (EI). The beam's modulus of elasticity (E) can be computed if (I) is known

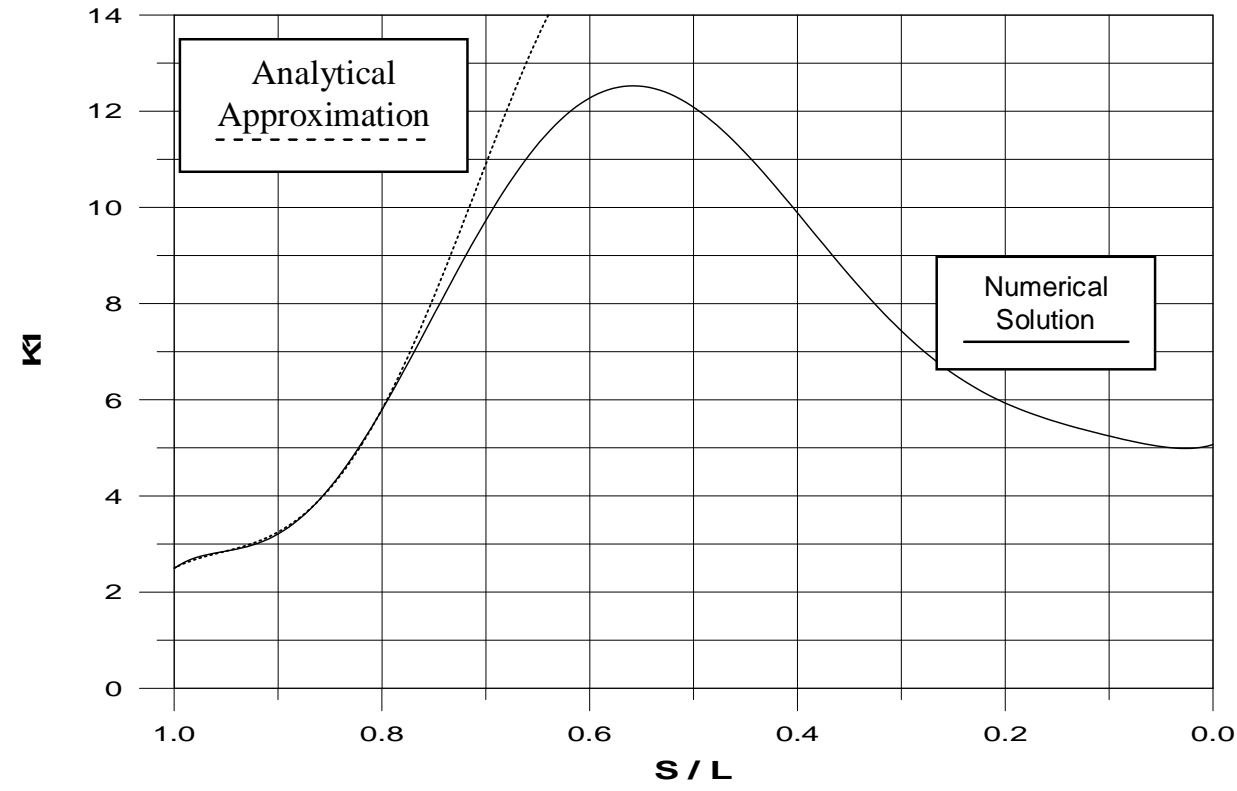

Fig.2 the Approximation of $\left(K_{1}\right)$ vs. the Function (S/L) of

\section{Beam with an Overhang}




\section{References:}

[1] Timoshenko and others. "Effects of Rotary Inertia and Shearing Deformations" John Wiley \& Sons. 1974

[2] Donald, J. and Wulpi, "Failures of Shafts", Metallurgical Consultant, 2000.

[3] Pellerin, R. F., “ A Vibrational Approach for Non-Destructive Testing of Structure”. Forest Product Journal. Vol.15 . No.3 pp.93-101. (1965).

[4] Rao, S.S., "Mechanical Vibration”, $3^{\text {rd }}$ edition, 1995.

[5] Sih, G. C. and Loeber, J. E. "Vibration of an Elastic Solid Shaft". J. Acoust. Soc. Am.44, pp. 1237-1245 (1968).

[6] Seto. W. W., Schaum's Outlines Series “ Theory and Problems of Mechanical Vibration". $4^{\text {th }}$ edition. Mc-Graw Hill Book Company, (1986).

[7] Miller, K. J., "An Introduction to Mechanics", Mechanical behavior of Metallic Materials, pp. 97-131, (1982).

[8] Timoshenko, S., Young, D.H., and Weaver, Jr., W. "Vibration Problems in Engineering". Fourth Edition. John Wiley \& Sons. (1974).

[9] Morrow, H. W., "Static and Strength of Materials", $3^{\text {rd }}$ edition, Prentice Hall, (1998).

[10] Dimarogonas A.D., Papadopoulos C.A., ,,Vibration of Beam in bending" , Journal of Sound and Vibration, 91, 583-593 (1983).England.

[11] Rice J.R., N. Levy, ,The part-through the surface in an elastic beam" , Journal of Applied Mechanics, 39, 185-194 (1972).

[12] Dimarogonas A.D., Massouros .G., ,, Torsional vibration of a beam " ,Engineering Mechanics, 15, 439-444 (1980).

[13] Timoshenko S. , Young ,D.H. Vibration problems in engineering. 4th ed. New York, NY. John Wiley \& Sons. (1974). 